\title{
CRITICAL LOADS OF ACID DEPOSITION FOR ECOSYSTEMS IN SOUTH CHINA - DERIVED BY A NEW METHOD
}

\author{
FULU TAO ${ }^{1,2 *}$ and ZONGWEI FENG ${ }^{2}$ \\ ${ }^{1}$ Agrometeorology Institute, Chinese Academy of Agricultural Sciences, Beijing 100081, China; \\ ${ }^{2}$ Research Center for Eco-Environmental Sciences, Chinese Academy of Sciences. \\ Beijing 100085, China. \\ (* author for correspondence, e-mail: Taofl@ns.ami.ac.cn)
}

\begin{abstract}
Critical loads of acid deposition for ecosystems in South China are derived by synthesizing the critical loads of acid deposition for soils, the critical loads of $\mathrm{SO}_{2}$ dry deposition for ecosystems, as well their exceedance. The results show in the southeast of Sichuan province around Chongqing municipality, the central and north of Guizhou province around Guiyang municipality, and the most areas of Jiangsu province, both the critical loads for soils and critical loads of $\mathrm{SO}_{2}$ dry deposition are exceeded. In Guangxi Zhuang Autonomous Region and some areas among Jiangxi, Zhejiang and Anhui provinces, the critical loads of $\mathrm{SO}_{2}$ dry deposition is the only restricting factor. There is no area where the critical load for soil is the only restricting factor in South China, so only the critical load for soil is not enough to be the basis to make sulfur abatement scheme.
\end{abstract}

Keywords: critical loads of acid deposition, $\mathrm{SO}_{2}$ dry deposition, exceedance, South China

\section{Introduction}

With regard to the effects of acid deposition on vegetation it is not only the indirect impact via soil, but also the direct above-ground exposure to certain concentrations and the above-ground uptake (dry deposition) which is important. However the critical loads of acid deposition, which are usually derived by soil acidification models so far, only reflect the indirect effects of acid deposition, rather than the direct effects of dry deposition (Tao and Feng, 1999a). The concept of critical loads has consequently been criticized because of the difficulties in estimating dry deposition and deposition via fog on the required scales.

In South China, the direct effects of $\mathrm{SO}_{2}$ and indirect effects of acid deposition (acidification) on ecosystems have both been demonstrated (Shen et al., 1995; Feng and Tao, 1998). Atmospheric concentrations of $\mathrm{SO}_{2}$ have been shown to cause direct damage to natural ecosystems and crops, as well as having health effects on local and regional scale, and are even supposed to be the more likely cause than acid deposition for the dieback of the masson pine trees in some areas of South China (Shen et al., 1995). So both the direct effects of $\mathrm{SO}_{2}$ and indirect effects of acid deposition on ecosystems should be simultaneously taken into account.

In this paper, the critical loads of acid deposition for ecosystems in South

Water, Air, and Soil Pollution 130: 1187-1192, 2001.

(c) 2001 Kluwer Academic Publishers. Printed in the Netherlands. 
China are derived by synthesizing the critical loads of acid deposition for soils, the critical loads of $\mathrm{SO}_{2}$ dry deposition for ecosystems, as well their exceedance. The use of the critical load map for making efficient sulfur abatement is also discussed.

\section{Description of the Study Area}

The region influenced by acid deposition in China lies mainly in South China, including Jiangsu, Anhui, Zhejiang, Fujian, Jiangxi, Hubei, Hunan, Guangdong, Guizhou, Guangxi Zhuang Autonomous Region, the eastern part of Sichuan and Yunnan provinces, Chongqing and Shanghai municipalities (Fig. 1). See also Tao and Feng, 2000a for detailed description

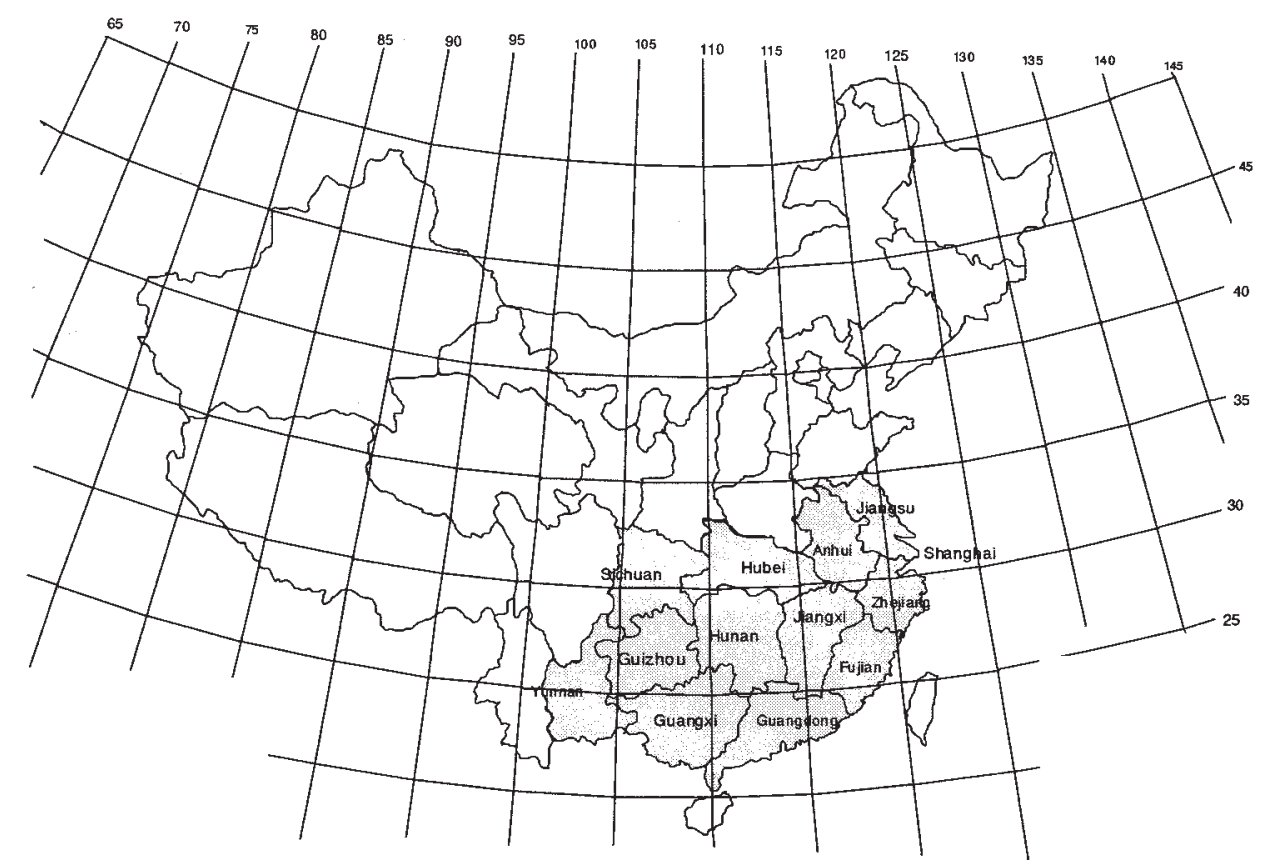

Figure 1. The study area 


\section{Critical Loads of Acid Deposition for Soils and their Exceedance}

\subsection{CRITICAL LOADS OF ACID DEPOSITION FOR SOILS}

Terrestrial ecosystem sensitivity to acid deposition in South China was assessed by combining the soil type, bedrock lithology, land cover and moisture profit and loss (Tao and Feng, 2000a). Then the critical loads of acid deposition for soils were mapped by combining the ecosystem sensitivity with site-specific studies conducted by MAGIC (Model of Acidification of Groundwater in Catchments) (Tao and Feng, 1999b); (Fig. 2).

The critical loads of acid deposition for soils in South China vary from 2.3 5.2 $\mathrm{gSm}^{-2} \mathrm{yr}^{-1}$ and increase from the southeast to the northwest on the whole. The most sensitive areas where the critical loads are less than $3.0 \mathrm{gSm}^{-2} \mathrm{yr}^{-1}$ are the south of Zhejiang province, the areas between Fujian and Guangdong provinces, the southwest part of Guizhou province and the central part of Guangxi Zhuang Autonomous Region.

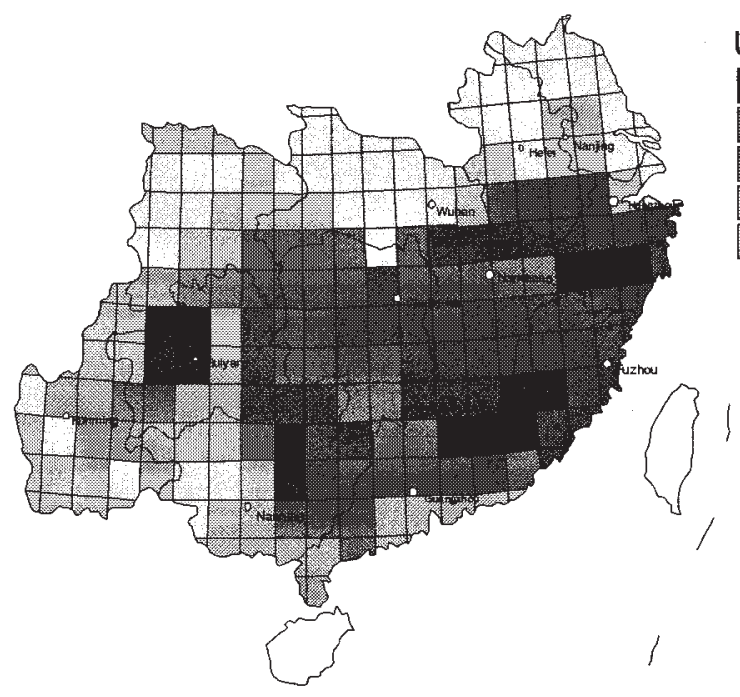

Unit: $\mathrm{gS} / \mathrm{m} 2-\mathrm{yr}$

$<3.0$ $3.0 \sim 3.5$

$3.5 \sim 4.0$

$4.0 \sim 4.5$ $>4.5$

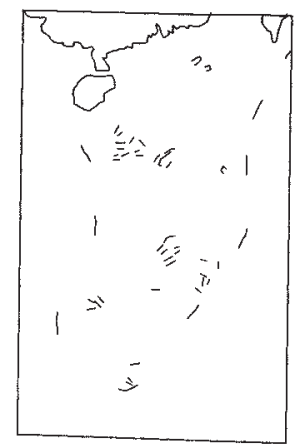

Figure 2. Critical loads of acid deposition for soils in South China 


\subsection{EXCEEDANCE OF CRITICAL LOADS OF ACID DEPOSITION FOR SOILS}

The exceedance of critical loads for soils can be derived from the critical loads of acid deposition for soils and the total sulfur deposition (Dai et al., 1998). In the Figure 1, if the values of $2.625 \mathrm{gSm}^{-2} \mathrm{yr}^{-1}, 3.125 \mathrm{gSm}^{-2} \mathrm{yr}^{-1}, 3.625 \mathrm{gSm}^{-2} \mathrm{yr}^{-1}, 4.125 \mathrm{gSm}^{-2} \mathrm{yr}^{-1}$ and $4.625 \mathrm{gSm}^{-2} \mathrm{yr}^{-1}$ are respectively selected to represent the ranges of $<3.0 \mathrm{gSm}^{-2} \mathrm{yr}^{-1}$, 3.0 3.5 $\mathrm{gSm}^{-2} \mathrm{yr}^{-1}, 3.5 \sim 4.0 \mathrm{gSm}^{-2} \mathrm{yr}^{-1}, 4.0 \sim 4.5 \mathrm{gSm}^{-2} \mathrm{yr}^{-1},>4.5 \mathrm{gSm}^{-2} \mathrm{yr}^{-1}$, and the highest deposition is selected as the representative value in every grid cell, then the excess of critical loads for soils in South China is computed and mapped as Figure 3. The areas with excess sulfur deposition located in the southeast of Sichuan province, the central and north of Guizhou province, and the most parts of Jiangsu province. The areas with the highest excess (above $2 \mathrm{gSm}^{-2} \mathrm{yr}^{-1}$ ) located in the areas around Chongqing municipality and Guiyang city.

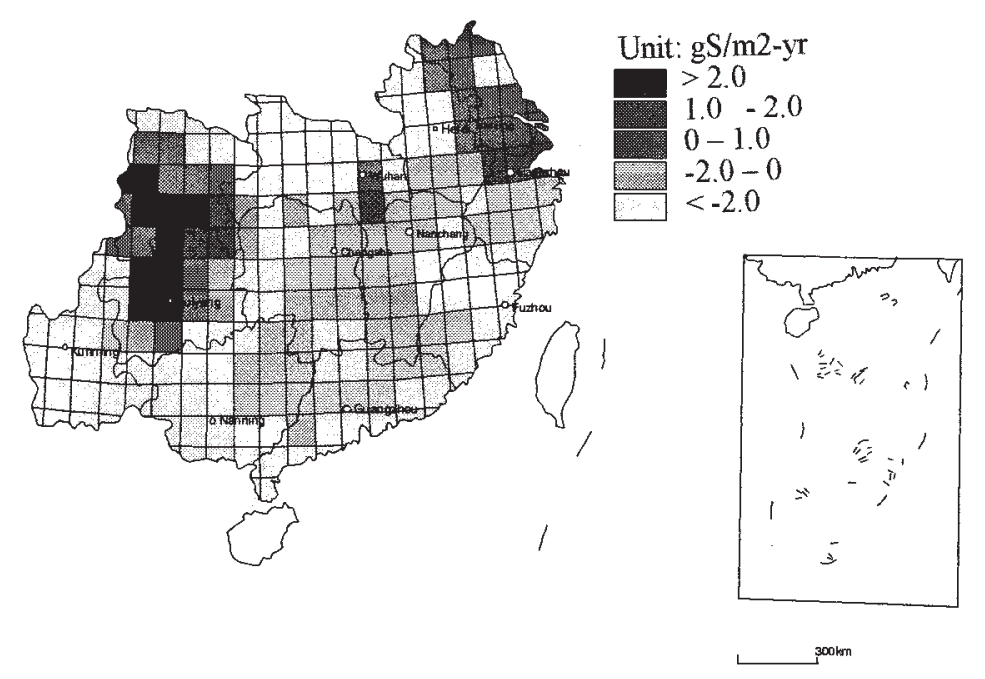

Figure 3. Excess of critical loads for soils in South China

\section{Critical Loads of $\mathrm{SO}_{2}$ Dry Deposition for Ecosystems and their Exceedance}

Atmospheric concentrations of $\mathrm{SO}_{2}$ can cause direct damage to natural ecosystems and crops, when above the $\mathrm{SO}_{2}$ critical level. However the critical level, represented as air concentration, may not be conveniently used to control pollutants emission as critical load, so it is transferred to equivalent $\mathrm{SO}_{2}$ dry 
deposition load called the critical load of $\mathrm{SO}_{2}$ dry deposition. The critical loads of $\mathrm{SO}_{2}$ dry deposition in South China were derived from $\mathrm{SO}_{2}$ dry deposition velocity and critical level of $\mathrm{SO}_{2}$ for vegetation by inferential technique. The $\mathrm{SO}_{2}$ dry deposition velocity was from simulation and observations. The $\mathrm{SO}_{2}$ critical levels for coniferous forest, crop and broadleaf forest are assumed to be annual average $20 \mathrm{~g} \mathrm{~m}^{-3}, 22.5 \mathrm{~g} \mathrm{~m}^{-3}$ and $25 \mathrm{~g} \mathrm{~m}^{-3}$ according to some references. The exceedance of the critical loads of $\mathrm{SO}_{2}$ dry deposition in South China was computed and mapped (see also Tao and Feng, 2000b).

\section{Synthesizing the Critical Loads for Soils and Critical Loads of $\mathrm{SO}_{2}$ Dry Deposition}

An attempt to synthesize the critical loads for soils and the critical loads of $\mathrm{SO}_{2}$ dry deposition on one map is needed to prevent confusion among policy-makers when considering abatement schemes. Firstly the restricting factor(s) should be determined in every grid cell according to the critical loads and the degrees to which they are exceeded. The restricting factors can be classified into four
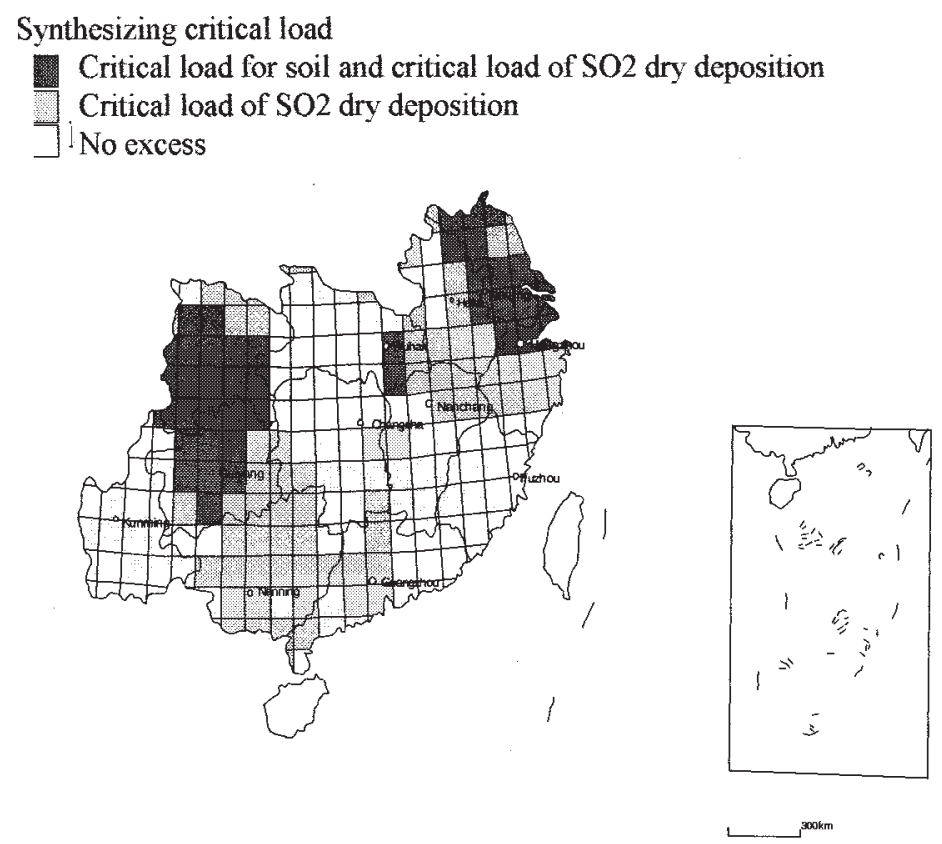

Figure 4. Synthesizing the critical loads for soils and critical loads of $\mathrm{SO}_{2}$ dry deposition 
categories: critical loads for soils, both critical loads for soils and critical loads of $\mathrm{SO}_{2}$ dry deposition, critical loads of $\mathrm{SO}_{2}$ dry deposition and no excess. The areas in South China are grouped into categories according to their restricting factors and mapped as Figure 4.

In the southeast of Sichuan province around Chongqing municipality, the central and north of Guizhou province around Guiyang municipality, and the most areas of Jiangsu province, both the critical loads for soils and critical loads of $\mathrm{SO}_{2}$ dry deposition are exceeded. The both are consequently the restricting factors there, and should be taken into account while the sulfur abatement scheme is made. In Guangxi Zhuang Autonomous Region and some areas among Jiangxi, Zhejiang and Anhui provinces, the critical loads of $\mathrm{SO}_{2}$ dry deposition is the only restricting factor. There is no area where the critical load for soil is the only restricting factor in South China, so only the critical load for soil is not enough to be the basis to make sulfur abatement scheme. In Fujian province, southeast of Yunnan province, most areas of Hubei and Hunan provinces, both the critical load for soil and critical load of $\mathrm{SO}_{2}$ dry deposition are not exceeded.

\section{Acknowledgements}

The research was funded by the Natural Science Foundation of China (No.40001023).

\section{References}

Dai, Zh., Liu, Y., Wang, X. and Zhao, D: 1998, Water, Air and Soil Pollution 108, 377.

Feng Z. and Tao, F.: 1998, J. of Environ. Science. 10(4), 505-509.

Shen, J., Zhao, Q. and Tang, H.: 1995, Water, Air and Soil Pollution 85, 1299.

Tao, F. and Feng, Z.: 1999a, China Environmental Science 19(2), 123.

Tao, F. and Feng,.Z.: 1999b, China Environmental Science 19(1), 14-.

Tao, F. and Feng, Z.: 2000a, Water, Air and Soil Pollution 118, 231.

Tao, F. and Feng, Z.: 2000b, Water, Air and Soil Pollution 124, 429. 